\title{
"WALL" Defining The Chinese Traditional Introverted Space Under The Influence Of Chinese Ethics
}

\author{
SHAN MAN \\ Tongji University
}

China has been understood as a land operated by walls since ancient times. During the traditional times, the settlement is made of courtyard buildings enclosed by walls completely. As the present age, the city has been arrayed by gated communities. They are enclosed by walls just like the way of ancient courtyard units. We believe the introverted space conception is continuing. As a result, there is a need to make qualitative research using socio-spatial patterns on how the walls define Chinese traditional space and the ethical reasons behind this.

We explore relations between "wall" and distinctive practices predicated on social structures. Informed by social space theory and morphology, empirical research using qualitative methods pairs with secondary and historical data in a study of "wall" in Chinese traditional space. Sociospatial meanings are explored through the analysis. This paper selects four patterns which are "wall" and buildings, "wall" and sequence, "wall" and view, "wall" and streets to represent how the "wall" as a device with particular roles defines Chinese ancient introverted space of specific social structures and values. We also explored the social structures and values reasons behind each pattern. As a result, "wall" is the most important way to define the introverted space even the introverted society of China. Through the analysis of walls, the paper draws some preliminary conclusions regarding the distinctly Chinese approach to the wall and the linked traditional social ethics reasons with an eye to the understanding of contemporary closed cities of China.

\section{INTRODUCTION}

Religion and ethics are the two most basic substances of the entire structure of society. Architecture culture serves as containers and expresses their ideas in a vivid way. Chinese architecture is an ethical expression, and in many ethical statements, "wall" is one of the most prominent. The first sentence of $\langle\text { The yellow emperor curtilage sutra }\rangle^{1}$ is : "Building is the key position of the Yin and Yang", and the dimensions of human ethics. "It means that building is the tool to combine the man and nature and meanwhile to coordinate social relations. As a result, ancient Chinese architecture and spatial form are not only understood as physical entity but more as a projection of the real world. The beauty of Chinese architecture lies neither in its architectural space nor in its physical structure; rather it is to be found between the space and what encloses it.
The Great Wall has been thought as the envelope of China since it was built until Qing Emperor Kangxi questioned it. To Kangxi, "wall" operated on the psychological rather than physical level. However, the initial concept of space is probably derived from this way of space division. After all, only when the space has been divided that it becomes comprehensible ${ }^{3}$. "Wall" as the most prominent architectural manifestation in describing Chinese space units was applied to enclose houses, palaces, temples, cities even the country. In China, these different types of architecture share the same spatial orders of being enclosed by walls to shape rectangle courtyards in different scales. (Fig.1) The walled space presents obvious introversion attempt within the defensible nature of the wall.

Chinese walled space can be described by the self-similarity of fractal geometry. From the country to the home, "wall" shaped the space form in different scales as isomorphic relations. The ways how wall operated to the space were similar to the specific grammar of Chinese space language. Hence, what first decided the system was patriarchal notion which is mainly focusing on the particular orders of domestic life. The farmers have to live on their land, which is immovable. Unless one has special talent, or is especially lucky, one has to live where one's father or grandfather lived, and where one's children will continue to live. That is to say, the family in the wider sense must live together for economic reasons. Thus there developed the Chinese family system, which was no doubt one of the most complex and well-organized in the world. A great deal of Confucianism is the rational justification or theoretical expression of this social system. The family system was the social system of China. Out of the five traditional social relationships, which are those between sovereign and subject, father and son, elder and younger brother, husband and wife, and friend and friend, three are family relationships. The remaining two, though not family relationships, can be conceived of in terms of the family ${ }^{4}$. Strict social hierarchy rules produced the space conceptions and they were widely accepted by the Chinese nation ${ }^{5}$.

Chinese ancient architecture should be analyzed as courtyard units instead of separated buildings like churches of western architecture. The most prominent element of the spatial unit is "wall". In Chinese ancient times, buildings had never existed as separated ones without "wall". All the buildings are influenced by walls to different degrees. The definition of space operated by wall can be exposed as four aspects as follows. 

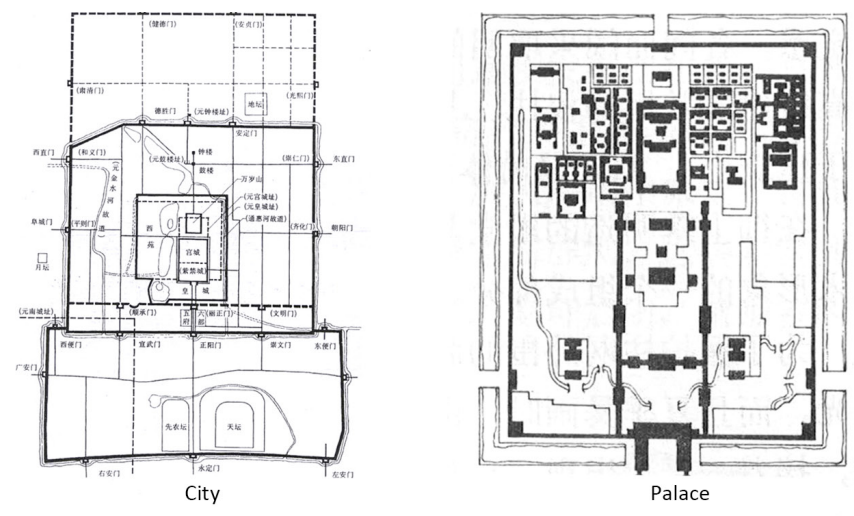

Figure 1: Same enclosure form in different scales. Dunzhen Liu,Chinese ancient architecture history (Beijing,China Architecture \& Building Press,2012),13

\section{2-1 BUILDINGS ARE EXTENSION OF WALLS}

The emergence of any architectural pattern in history is closely related to a new way of life. In Chinese traditional architectural culture, "home" as a way of life combining with "court" as a space form, formed a "courtyard" to be the type of habitat ${ }^{6}$. Courtyard house was the product of the most typical cultural ideal of family.

In this courtyard living pattern, wall became the primary element in the realization of the courtyard, resulting in two spatial features:

(1) First come walls then the buildings in the courtyard enclosure generating process. That makes the wall become more "architecturalized". To be specific, people cannot live in a "wall", but the ancient Chinese "wall" have two-slope roof, copestone, brick eaves and lower alkali wall, so the wall is entirely regarded as "a small building" with fully designed head and foot. On the contrary, buildings inside seem like to grow from the walls and could be described as the enlargement and extension of the walls. (Fig.2) Walls are becoming architecture within buildings being reduced to attachments of the walls.

(2) The buildings shaped as the enlarged walls had the inner boundary of the body weakened. It exists as several windows and doors made by easy-broken paper which is beyond the functional requirements ${ }^{7}$. On account of the prior status of the wall, outer boundary of the courtyard becomes the more solid one which is known as "being" of Chinese culture, on the other hand, the internal division inside the walls is more of emptiness known as "Non-being". As the walls stand out as "being", it might be seen the building entities disappearing within only four big walls left.

The reason behind the space forming is Chinese ethical concept. To live in the ancient society, patriarchal philosophy instead of the laws had decided the formation of life mode.
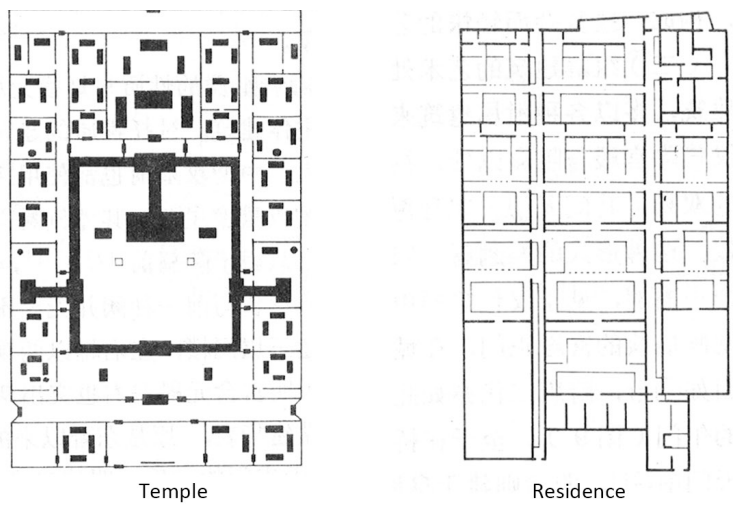

The boundary shaped by walls is consistent with the boundary of a family, which comes from the family oriented society. The courtyard pattern is introverted to reject the world outside. There is a private world of the family inside the walls where domestic life operates all the connections and rules. Besides, the walled space unit is holding not only living requirements but also all the functions originally provided by urban and nature. Courtyard can be used as place to sacrifice, hold weddings as well as make dialogue with nature. The Confucianism teaches people to regard family as social microcosm, which makes residence space exist as a micro universe.

\section{2-2 WALL AND SEQUENCE}

Another Chinese walled space feature can be described as multiple layered sequence. Single Courtyard units are connected in series. One can understand Chinese space by passing through the walls serving as barriers of sequential courtyards. (Fig.3) Space units are embedded in order to diminish accessibility. Courtyard sequence grows more at the longitudinal direction than the horizontal direction. This structure produces a large amount of deep space which is difficult to reach.

Chinese architecture pays more attention to the representation of spatial sequence than the buildings themselves. We might find that all the buildings are presenting in the same shape and façade. This phenomenon strengthen the mysterious sense of the space because all the walls and gates appear almost the same. The logic of the space sequence can only be found by passing through the layered walls enclosing courtyards.

Behind the Chinese space concept is the social structures known as hierarchy. Hierarchy has to be showed in architecture. According to the introverted ideology, the more difficult one space can be reach the more dignified sense will be showed. Hence, the higher class of the society one belongs to the more enclosed space he should use. Among all the courtyards in series, the deepest one is always for the highest elder members of the family. That is the meaning of sequence. One poetry saying "One can never know how much depth the courtyard is" well expressed the point of Chinese space. 


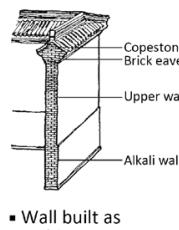
- Wall built as
architecture

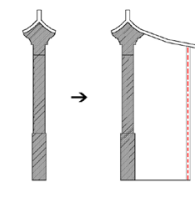
- Buildings extended from wall

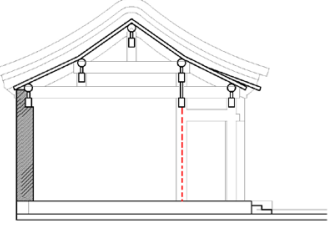
Doors - inside boundary - emptiness
- Walls - outside boundary - solidness

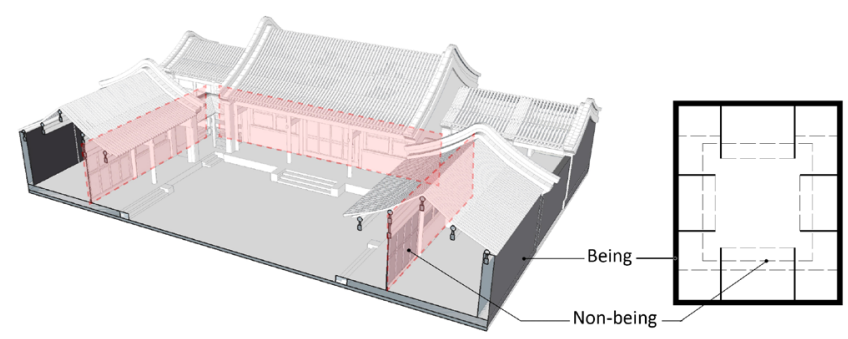

Figure 2: Buildings are extension of walls. (Drawn by author)

This space conception can also be found in traditional gardens and paintings. The paintings are always served as scrolls and have to be opened from the beginning to the end inch by inch. The whole picture cannot be seen at one sight. So the content of painting must be arranged in particular orders to tell a story so as to cooperate with scroll form.

\section{2-3 WALL AND VIEW}

As the ancient spatial conception, the height and distance of wall is set based on the view. View communication between the two sides of the walls is forbidden. "Mysterious courtyards" should not be seen from outside of the walls. In Warring States Period, tall buildings were still prevailing as the symbol of power. But afterwards they were only built alone like a monument instead of built in the courtyard sequence. Because it was inconsistent with the spatial sequence for shaping the "mysterious courtyard". The greatest problem to introduce high buildings into the courtyards made by walls is that it might break the concept of introverted spatial organization. To insert a high building to the courtyard series would break the original gentle vertical skyline ${ }^{8}$.(Fig.4)

As the interior buildings rises a certain height, the outer walls need to rise as well for a certain proportion or retreat a certain distance to ensure the view isolation between inside and outside. Like in the Forbidden City, if the main palace inside the Forbidden City is built higher than other ones, to make this happen, the boundary walls have to be set away from the palace for a certain distance to fulfil the sight isolation.This situation also happens in Beijing "Hutong". People standing in the "Hutong" roads cannot see anything from the courtyards except the walled boundary.

There is a significance line between inside and outside in Confucian standards. So the traditional architecture guides people's behavior by dividing the inner and outside space, and indicates the relation mode between different people by making use of the symbol system. The isolation of in and out was showed not only on weak accessibility but also on view connection. This line was almost operated by walls. The main buildings inside the walls can only been seen or accessed by people who has the specific qualifications. Obviously the emperor can reach anywhere in Chinese land without limitations at all.

Another reason of the isolation is about the ethical significance of individual solitude. Etiquette of Zhou Dynasty taught people to value being alone. Chinese people are good at being alone even today. As a result, traditional architecture was operated to give limits to human behaviors. This concept can be presented mostly on the independence of each courtyard and the isolation of view of each enclosures. Chinese spatial form is strongly influenced by the ethics, culture and social life patterns.

\section{2-4 TREE STRUCTURE}

The street system in Chinese traditional cities has always been of secondary importance. Streets are just holding the function of connecting the courtyard units, while the form and other variety functions of street were neglected. In the traditional cities of China, architecture barely related to the city which was presenting the space introversion. City public space was not regarded seriously, and this situation could be even worse before the Song Dynasty.

The low position of streets in Chinese cities is quite related to the important role of the walls. Each living unit takes a courtyard as a center, surrounded by walls, and each units are arranged one after another to form a series pattern. There is just one spot to communicate with the street for each series which is the first gate of each family. This forms a tree structure which showed all the buildings are only linked to the tree trunk without a direct connection to the street. (Fig.5) The buildings and courtyard space are hung as fruits at the ends of this tree structure. Standing on the street, you can only see the walls of every enclosures along both sides of the street, and there is no sense of the inner world that can be got. This pattern was also used in palaces and temples that buildings were only connected to the outside space through the gate. From the outside of the Forbidden City, only four huge red walls can be seen.

For the good of city, the residence units should be connected to the city system as parallel relations instead of tree structure. If each small unit is a tree structure, the city buildings would form a forest structure. In this case, although various buildings co-exist in the same space of the city, they were not communicating with each other even the city at all. As a result, the construction of the urban space lacks the participation of each building, each of which is only related to the 

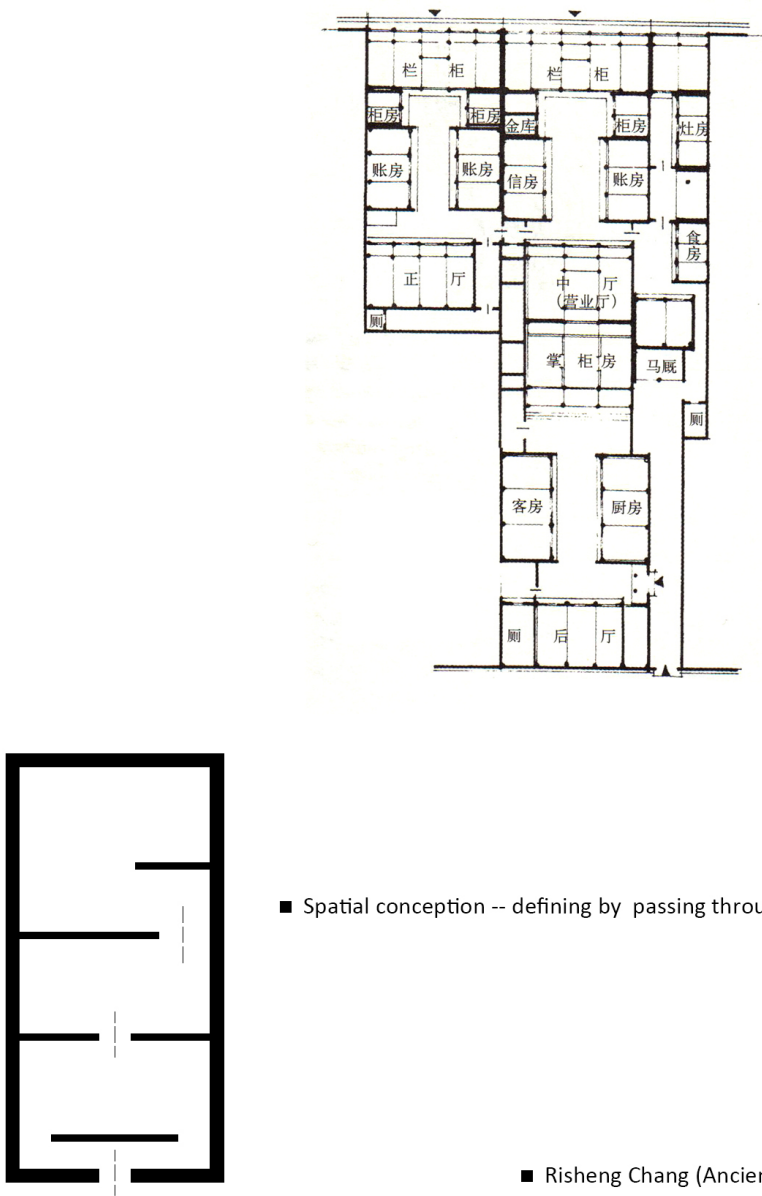

- Spatial conception -- defining by passing through walls

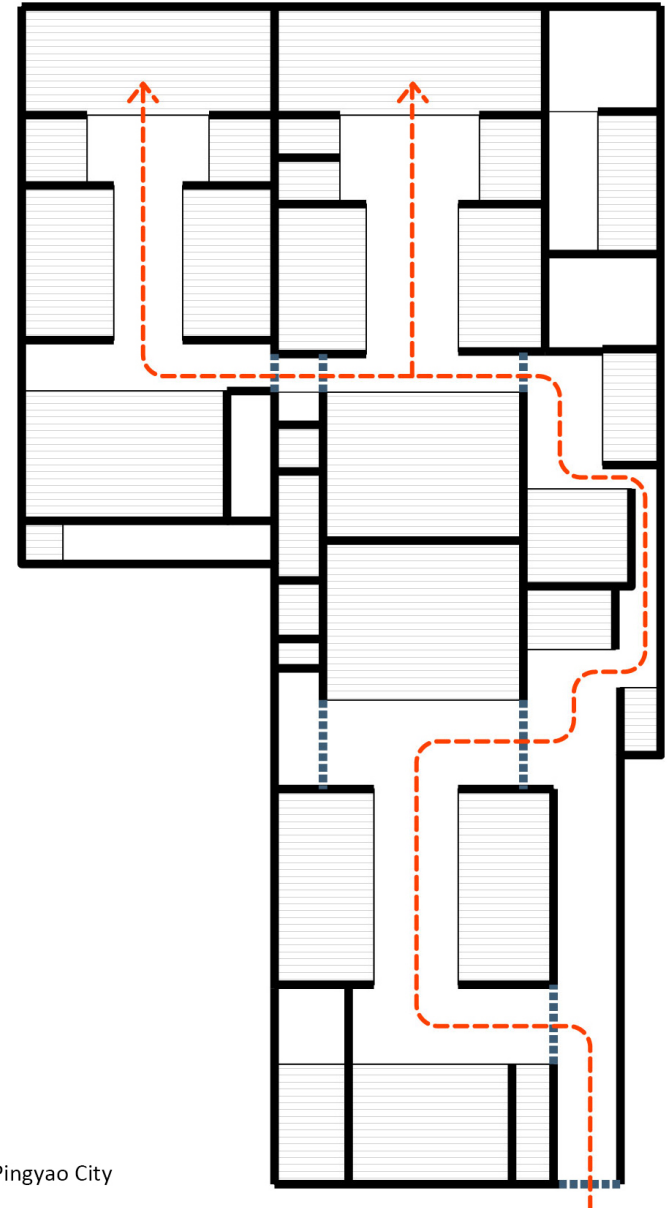

- Risheng Chang (Ancient Bank) in Pingyao City

Figure 3: Weak accessibility of the courtyards and sequence is experienced by passing through walls.(Drawn by author)

city by entrances and the other parts of the units are entirely isolated from the city.

The emergence of such urban space is closely related to China's ethics. China's introverted spatial conception and the hierarchical etiquette of Confucianism have a profound influence on the spatial structure. This structure emphasizes the ritual and hierarchy of the whole city and the isolation between subsystems. At the same time, the tree structure reflects the pedigree of the family, the trunk and branch of the tree is presenting the hierarchical relations of all members from the whole family.

\section{CONCLUSION}

China's spatial form is closely related to Chinese lifestyle and social ethics. Particular Chinese ethics related to particular cultural ideals of family motivate a distinctly Chinese approach to the wall. Hierarchy, etiquette and patriarchal system constitute the main part of the particular ethics to influence the space. It can be said that the ethical orders have created the ancient space pattern. The wall is the main method of forming the traditional introverted space. This paper selects the element of wall to make a socio-spatial analysis, which shows that the status of the wall in Chinese space cannot be replaced. Without the wall, the Chinese space will no longer exist.

India ancient Mandala graphics, similar to the China "Nine boxes", is known as space schema. The mandala in Sanskrit means a "circle", with clear boundary and center, which is an expression of space organization in ancient times. The concept of "circle" in architecture existed in many ancient society, and the Chinese "Nine boxes" has the same meaning as the "circle". Therefore, the concept of enclosed space has existed since very ancient times, and the wall is the best approach to make the enclosure happen.

The construction of the inward and outward can be expressed in the space organization. The western architecture presents as buildings surrounded by emptiness, while in Chinese is opposite. Chinese culture and Chinese people are consistent with Chinese traditional space. The structure and form of Chinese culture and the introversion of space are projected in the architectural organization. Technology develops fast, but culture notion, people's psychological structure and thinking 


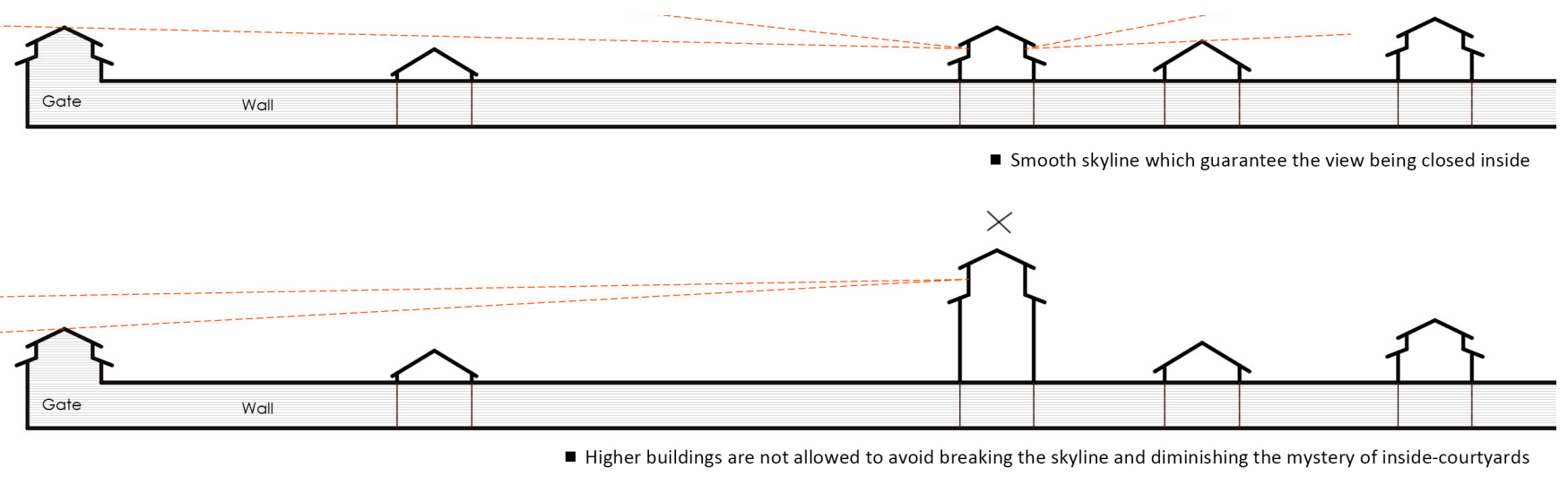

Figure 4: The view inside has to be isolated from outside (Drawn by author).

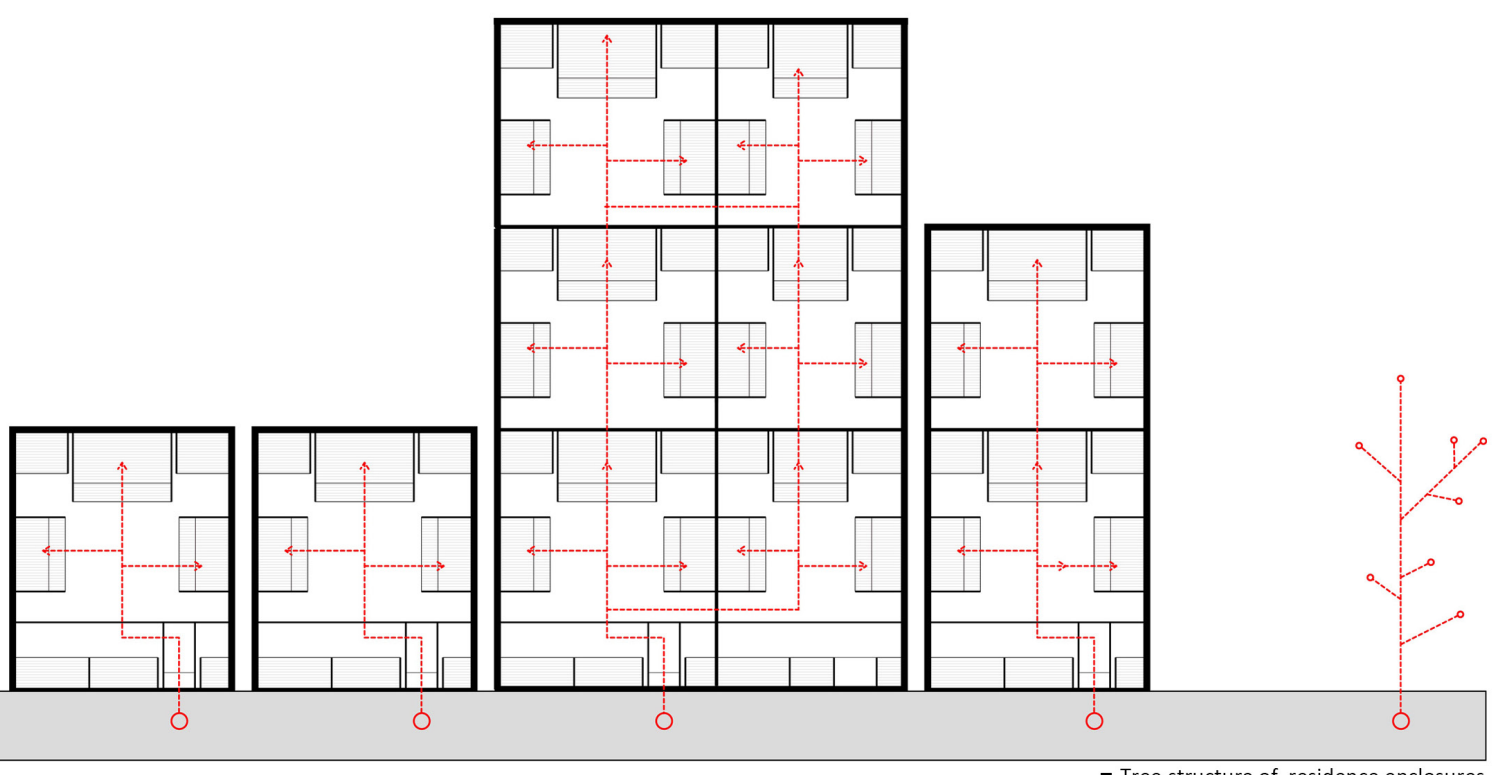

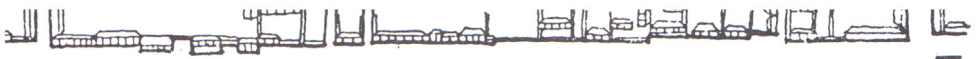
焦

- Beijing Hutong of Qing Dynasty

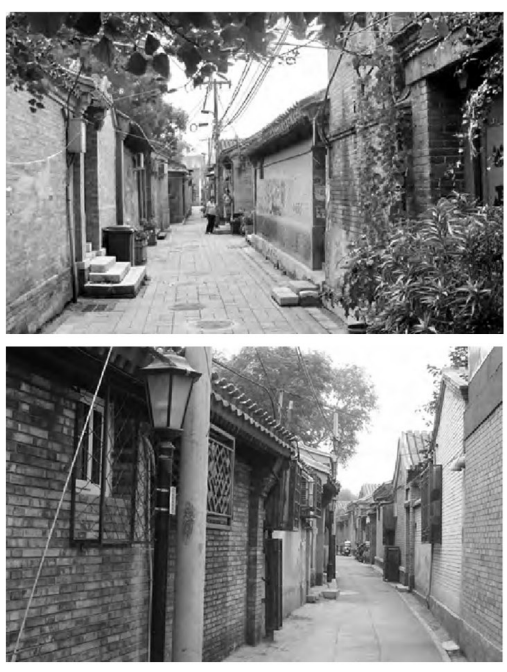

- Beijing Hutong streetscape 
habits have been changing very little in the past few thousand years. Even though patterns of life today have been changed by technology, the particular Chinese introverted spatial conception continues. For example, the massive construction of gated communities is taking place because of Chinese inward demand which has triggered replication of such space production. It is the inheritance of people's culture and space ethics. The material wall today have mostly disappeared and the fast architectural development is ignoring the psychological "wall" in the city. Facing design tasks in the future, how to deal with the Chinese traditional "psychological wall" might become a question. Spatial form cannot exist without social ethics. Therefore, from an ethical point of view, understanding what we were in history is the best exploration of the future.

\section{ENDNOTES}

1 The Yellow Emperor is the very first Emperor of China.

2 The terms "Yin and Yang" mean the two sides of the world. In Chinese philosophy, Yin and Yang are the compositions of the universe.

3 Xiaodong Li, Chinese Conception of Space (Beijing: China Architecture \& Building Press,2007),111-112.

4 Youlan Feng, A Short History of Chinese Philosophy (Beijing:Peking University Press,2012), 21.

5 Qing Chang, Chinese Architecture Agenda (Shanghai: Shanghai People's Publishing House, 1998), 2.

6 Wuqing Wang, "From settlement to urban-Chinese traditional architecture culture features," Architecture and Planning Theories, no. 6 (2006): 31-32.

7 Wenyi Zhu, "The code of Chinese ancient space," Architectural Journal,no.6 (1994): 12-16.

8 Lumin Wang, The Culture Gene of Chinese Traditional Architecture (Shanghai: Tongji University Press, 1997): 127. 